A conceptual model for analyzing the dynamics of
the value of the project, achieved as a result of engineer-
ing, under conditions of uncertainty has been developed.
In the methodological context, the proposed approach
is based on an array of isovalues, each of which corre-
sponds to its own level of optimism in forecasting the
cash flow for the project. With the increase in the effi-
ciency of the project due to engineering, the entire array
of iso-value lines'changes its geometrical position, mov-
ing further from the origin (in the four-dimensional space
"time-benefit-cost-risk"). The proposed model includes
three stages. At the first stage, input information is col-
lected and the corresponding analysis is initiated. The
result of the second stage is a multivariate cash flow
forecast and calculation of the benefit-cost ratio (BCR)
and its changes for each scenario. The third stage pro-
vides the calculation of the expected BCR and its change,
an assessment of the risk of making an erroneous deci-
sion and changing this risk as a result of the engineer-
ing session. The model makes it possible to calculate the
achieved proportion of the static and dynamic vectors of
change in the value of the project. In the example con-
sidered, the share of the dynamic vector of growth in the
value of the project was found to be $35.47 \%$ The model
has an environmental property - the assessment of the
success of value engineering under conditions of uncer-
tainty is carried out on the basis of the annual total ben-
efits and the annual total costs throughout the project
cycle. Thus, the analysis takes into account the impact of
the project on the environment, which is reflected in the
risk assessment. The given case testifies to the feasibility
of applying the model in the practice of engineering the
value of construction projects
engineering, resource consumption, innovation manage-
ment

\section{DEVELOPMENT OF CONCEPTUAL MODEL OF PROJECT VALUE DYNAMICS ANALYSIS IN CONDITIONS OF UNCERTAINTY}

\author{
O lexander Bugrov \\ $\mathrm{PhD}$, Associate Professor \\ Department of Project Management \\ Kyiv National University of \\ Construction and Architecture \\ Povitroflotsky ave., 31, Kyiv, Ukraine, 03037 \\ O lena Bugrova \\ Corresponding author \\ $\mathrm{PhD}$, Associate Professor \\ Department of Economic Theory \\ National University of Kyiv-Mohyla Academy \\ Skovorody str., 2, Kyiv, Ukraine, 04070 \\ E-mail: bugrova.olena@gmail.com
}

\section{Introduction}

Value engineering aims to increase the utility of a project per unit of resources required to implement it. In construction projects, this methodology can be applied multiple times and at different stages. As a result of each engineering session of value, thanks to the proposed technical solutions that can relate to any aspect of design and in any combination, the project reaches its level of value. For each of these states, the project can predict the cash flow and calculate the dynamics of the efficiency of investments in construction, achieved through engineering. However, events in the future, under the influence of many factors, can go according to different scenarios, and it is impossible to guess exactly which ones. Therefore, the creation of a conceptual model for analyzing the dynamics of the value of a project in conditions of uncertainty and acceleration of scientific and technological progress is a relevant task.

In [1] it is indicated that the creation of a design as its core has a definition of a strategy that requires rational calculation to make the most appropriate decision, and it is said: "the importance of calculation in design becomes increasingly clear in new and sometimes surprising ways".

The importance of this topic in construction projects is especially high due to the following reasons. Firstly, the im- plementation of construction projects is usually associated with significant investments, causing increased attention to the issue of effective use of capital investments. Secondly, such projects often require the use of large amounts of natural resources and can have a negative impact on the environment. Thirdly, the life cycle of such projects is rather long, and, therefore, anticipating the development of events for years to come requires the use of approaches such as the theory of probability. These key aspects are the general context for this study.

The high relevance of the topic is associated with a modern requirement, in [2] it is indicated as follows: "the moment must be seized to take advantage of this unique window of opportunity to redesign a more sustainable economy”.

Engineering of value has proven its performance in wide practice, but it requires development on the basis of fundamental and applied scientific research. In the modern world, innovations appear very often and have already become a key factor in capital reproduction. Due to the long duration of construction projects, additional opportunities arise for the introduction of new technologies in them. At the same time, the current state of development is characterized by increased unpredictability. Environmental challenges and the aggravation of the problem of using natural resources should be taken into account when justifying the feasibility of a 
design for a project. The potential for extensive development in the global sense is almost exhausted. This indicates the feasibility of developing a sustainable development-oriented model for analyzing the dynamics of the value of a project under conditions of uncertainty.

\section{Literature review and problem statement}

In work [3] it is noted that "value creation theory proposes that design is a factor early in the product development process". In [4] it is indicated that in the construction industry, behind the traditional approach, design covers predesign, schematic design, design development and construction documents. At the same time, according to the integrated project execution approach, the role of design in the early stages increases and in such a strategy the stages are called: conceptualization, criteria design, detailed design and implementation documents. These works define the stages of the project, on which attention is focused on creating an effective design, however, the models for making technical and economic decisions are not disclosed.

As indicated in [5], "value-creating innovations are pursued to maximize the value that an innovation holds from the customers' point of view" is the indicator that adequately reflects the value of the project both from the perspective of the consumer and the investor and other interested parties to the project [6] So, it is advisable to develop research in the field of analysis of the dynamics of the value of a project in conditions of uncertainty on the basis of this indicator.

Innovation refers to the introduction of new ideas or technologies to create value in fundamentally different ways than in the past [7]. Some of the value will be captured again by the firm, and the rest - by project partners and other stakeholders [8]. In construction projects, quality of work and environmental protection are strongly linked to cost and value [9]. Within the framework of a construction project, new engineering solutions will not be recognized as expedient without an appropriate investment justification. In work [10] it is noted that the final task of design is to assess the innovation in the product that must be produced or implemented. Thus, research should include the use of a mathematical apparatus that can be used to assess the effectiveness of innovations in design, taking into account the impact of the project on the environment.

The expected value to be created is determined at the very beginning of the project and then this "reference point" serves as an initial basis for comparison with subsequent results [11]. So, in the created conceptual model, the dynamics of design improvement has to be analyzed in comparison with its previous states, starting from the baseline.

Despite the presence of a significant number of criteria, in fact, to determine the feasibility of projects, mainly only three are used: the net present value (NPV), the internal rate of return (IRR) and the payback period (PP) [12]. In [13], it is noted that NPV is usually recommended as a key criterion. For example, in [14] NPVs are applied to assess various technologies. The initial version of the NPV method considered cash flows as deterministic, and later the approach was refined for conditions of uncertainty [15]. The expected net present value (ENPV) method relies on several plausible scenarios for the development of events [16]. Similarly, it happened in the development of other methods (criteria) of project evaluation. For example, one of the cases of using multivariate forecasting within the framework of the benefit-cost ratio (BCR) method is given in [17]. In [18], the BCR method (criterion) is the basis for the "risk-cost-benefit" analysis. In work [19], the "fuzzy BCR" method was applied to determine the feasibility of production technologies. The BCR criterion is convenient for application in the system of interaction of various decision-making groups [20]. At the same time, in conditions of uncertainty, traditional approaches to assessing investment projects do not provide adequate support for making the most appropriate decisions [21]. The issue of industry responsibility for the state of the environment in modern conditions is one of the most important topics [22]. An extensive development path associated with an ever-increasing consumption of resources causes exacerbation of environmental problems [23]. A cost-benefit analysis should evaluate investment projects taking into account their impact on the environment [24]. At the same time, it is not so much about construction waste [25], but about the impact of the project on the ecosystem and the dynamics of natural resources [26] during the entire project cycle. So, this area, especially in the context of green engineering, needs to be improved.

Earned Value Management (EVM) is one of the analytical tools that helps the project manager to monitor the status of a project in the face of uncertainty [27] and can be enhanced by risk management techniques [28]. This method is widely used in the construction industry [29]. Work [30] is devoted to probabilistic modeling in the context of controlling the timing and costs of an investment construction project, based on the joint application of the Program Evaluation and Review Technique (PERT) and EVM. However, this approach does not provide control over the dynamics of the project value arising from engineering. Traditional EVM does not cover post-construction project data. At the same time, the benefits of the project manifest themselves mainly after the commissioning of the construction object, which means that it is necessary to analyze how engineering solutions affect the efficiency during the entire project cycle [6]. The recent idea of creating Earned Green Value Management (EGVM) aims to cover the entire project cycle and take into account the impact on the environment [31]. However, this model does not take into account the cost of money in time and is not an assessment of the economic efficiency of the project [6].

The main goal of value engineering (value management-VM) is to achieve the most effective project result. [32] emphasizes this very goal, although it focuses more on the question of the role of VM in cost control. So, the focus of research should be directed primarily to maximizing value, not limiting costs.

Investigating the issue of the dynamics of value, work [33] notes that one of the areas of concern for the environment is the development of business strategies to extend the life cycles of production products. But, on the other hand, the acceleration of scientific and technological progress usually leads to the fact that objects are more likely to become technologically obsolete. In addition, it should be emphasized that "construction is the most difficult activity in terms of its dynamic and complex nature" [34]. Thus, the issue requires a comprehensive solution using the theory of the dynamics of the project value [6] and the value engineering methodology [35].

The higher the forecast uncertainty, the greater the project risk [36]. Uncertainty is changing, inter alia, due to the 
introduction of new technologies that affect the deviation of the value of the project from the predetermined value. Despite this, an effective control process must track the dynamics of value in the face of uncertainty [37]. At the same time, practice tends to assume that risk management itself adds value to the project [38]

All this allows to assert that it is expedient to conduct a study on the development of a model for analyzing the change in the value of a construction project achieved as a result of engineering, under conditions of uncertainty. Moreover, such a model for assessing design improvement should be consistent with the task of protecting the environment.

\section{The aim and objectives of research}

The aim of research is to develop a model for analyzing the dynamics of the value of a construction project in conditions of uncertainty, with an assessment of the change in investment risk, which took place as a result of the introduction of new engineering solutions in the design. This will make it possible in each individual project to achieve a better understanding between engineers and investors in choosing the most appropriate alternative for improving the design, taking into account the possibility of the course of events according to various options.

To achieve the aim, the following objectives were set:

- to characterize the properties of isovalues in conditions of uncertainty;

- to develop a conceptual procedure for analyzing the dynamics of the value of the project, based on the forecast of cash flows for several possible scenarios;

- to propose an appropriate analytical model, illustrating it with an example.

\section{Materials and methods of research}

In the course of the study, information was used regarding the expected cash flows for the construction of a construction plant.

During the study, the following methods were applied:

- analysis, synthesis, induction, deduction, theory of the dynamics of the value of the project (to determine the properties and graphical display of isovalues in conditions of uncertainty);

- the method of functional analysis of systems/Functional Analysis System Technic - FAST (for the formation of a procedure for analyzing the dynamics of the value of the project as a result of engineering);

- modeling, formalization, cost-benefit analysis methodology, probability theory (to create a conceptual model for analyzing the dynamics of value under uncertainty).

"Invented in the late 1960s, FAST perfected Value Analysis. The purpose of this method is to create a new design, however, it can be applied to improve an existing system. By its principle, FAST allows to sequence the functions performed by the system, analyzed." [39].

In [40], it is noted that "the economist Georgescu-Roegen's work on entropy and thermodynamics in economic processes demonstrates how natural resources are degraded by economic activity". The theory of the dynamics of the value of the project is based on three laws that closely correspond with the laws of thermodynamics [6]. Consequently, this aspect of the methodology is consistent with the statement given in [41] that in ecological economics the laws of thermodynamics profile the laws of economics.

The calculations, within the framework of the study, are based on the "benefit-cost" coefficient, which has certain features and is represented by formula (1). BCR project, in the context of investor monitoring of value dynamics, is the ratio of the sum of the discounted benefits to the sum of the discounted costs:

$$
B C R=\frac{\sum_{n=0}^{\tau}\left(P_{n} \cdot k_{n}\right)}{\sum_{n=0}^{\tau}\left(C_{n} \cdot k_{n}\right)},
$$

where $P_{n}$ - funds inflows (benefits) in period $n$;

$C_{n}$ - payment of funds (expenses) in period $n$;

$k_{n}$ - discount factor that takes into account the deprep ciation of funds from the start of the project in the period (year) $n$ [6].

It should be noted here that the traditional approach to calculating the BCR indicator, or as it is also called the profitability index (PI), is somewhat different. For example, according to [42], this criterion is calculated as the quotient of dividing NPV by the initial investment.

\section{Research results of the impact of engineering on the project value, taking into account the risk}

5. 1. Properties of isovalues in conditions of uncertainty

The properties of the graphs of isovalues without taking into account the influence of the uncertainty factor are formulated in [6]. Let's give an example of how the points of states of the project are formed on the same line of isovalue. As shown in [43], speeding up by using a tighter work schedule gives a gain in time, however, it is associated with the mirror risks of higher costs and late completion of the execution.

Provided that the model assumes only one, "accurate" cash flow forecast, each step of engineering is considered to bring the project to its own single level of dynamic value. However, in the presence of several scenarios of cash flow, each of them has its own isovalue line in the four-dimensional coordinate system "time-benefit-cost-risk".

The need for multiple forecast scenarios is consistent with the figurative statement: "According to traditional assumptions, the future is singular, like the end of the road. However, according to complimentary assumptions, the future is plural, like the branches of a river delta" [44].

At the same time, the line of isovalues, which corresponds to the pessimistic forecast of the cash flow for the project, is closer to the origin of coordinates, and the optimistic one is farther from it (Fig. 1). The line of isovalue, which corresponds to the most probable forecast, is located in the middle of the above lines.

Based on the above, the definition of isovalue lines in comparison with that indicated in [6] should be slightly changed. The scenario based on the balance of optimism and pessimism is the most probable, and its isovalue line is the key one in the analysis. The more pessimistic the expectations are, the closer to the origin the corresponding isovalue line becomes. On the other hand, the more optimistic the forecast is, the farther from the origin is the corresponding isovalue line. In addition, the farther the isovalue is from the key line, the less likely this scenario is. 


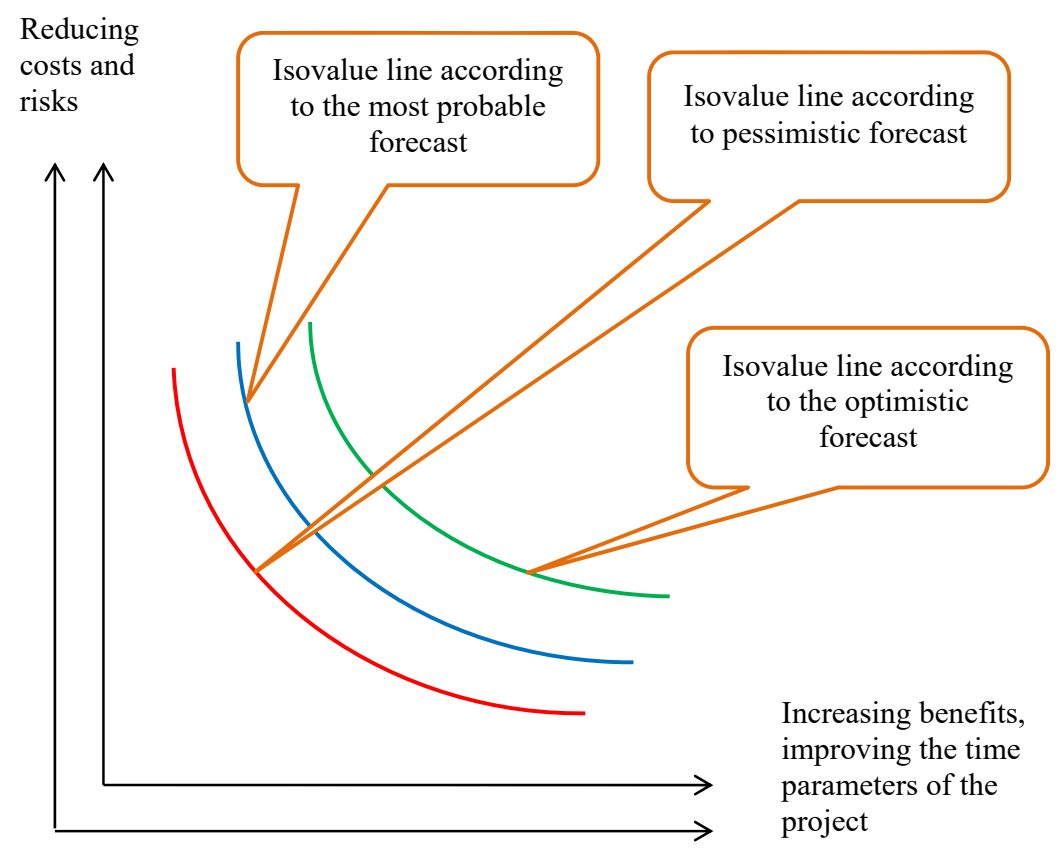

Fig. 1. Conditional image of lines of dynamic project value equivalence (according to the optimistic, pessimistic and most probable forecast)

With an increase in the efficiency of a project due to engineering, the entire array of isovalue lines (for the entire set of forecast scenarios) changes its geometrical position, moving further from the origin of coordinates of space. So, the following illustrative situation may arise. As a result of the current session of engineering, the isovalue line according to the pessimistic forecast will move to the place where earlier (at the previous session) was the isovalue line according to the most probable forecast. In turn, the isovalue line according to the most probable forecast will move to the place where the isovalue line according to the optimistic forecast used to be. According to the optimistic forecast, the new location of the isovalue line will be even further from the origin of coordinates of the corresponding four-dimensional space.

\section{2. The procedure for analyzing the dynamics of the} project value as a result of engineering

For mutual understanding and convenient convergence of the positions of investors and the value engineering team (design team), it is advisable for the project to develop a model for analyzing the dynamics of efficiency using Functional Analysis System Technic (FAST). This technique is a powerful and popular tool for building as logical procedures as possible.

The key task of such an analysis is to assess the dynamic component of the impact of engineering carried out during the current session on the effectiveness of the project (Fig. 2). It is this influence, assessed by the change in $\mathrm{BCR}$ that characterizes the success of the value engineering team from the point of view of investors and other project participants, provided that they respect nature [6]. However, as follows from the previous section, in conditions of uncertainty, it is appropriate to make several forecasts (scenarios) of cash flows, in accordance with different degrees of optimism/pessimism. Each scenario will have its own BCR.

The scope of the VDA study consists of three stages. At the first stage, according to the chronology of events, steps (blocks) are taken to collect initial information and initiate the corresponding procedure. In FAST terminol- ogy, these steps refer to "lower scope" functions. Verification (validation) of the relevant data from the previous engineering session is carried out when it took place. When analyzing the first session of value engineering, BCR for all forecast options is compared with one.

At the second, intermediate stage, according to the chronology of events, steps are taken for multivariate forecasting of cash flows and calculating BCR and $\triangle \mathrm{BCR}$ for each corresponding scenario of the expected conditions of the project.

At the third stage, according to the chronology of events, steps are taken to calculate the EBCR and ${ }_{\Delta} \mathrm{EBCR}$, as well as to assess the risk of making an erroneous decision and calculate the change in such risk due to the introduction of the proposed engineering solutions. In addition, the proportion of dynamic and static vectors in the total change in the value of the project can be calculated here. In FAST terminology, these steps refer to "upper scope" functions.

So, the third stage of the procedure is decisive. In this regard, the following should be noted here. The calculation of the expected benefit-cost ratio (EBCR) is similar to the known calculation of the expected net present value (ENPV), however, within the proposed conceptual model, it has some characteristic differences. The key criteria for assessing the dynamics of the value of a project under conditions of uncertainty, EBCR and EBCR, are calculated not on the basis of net cash flows, but on the basis of separately taken annual total benefits and annual total costs of the project. Thus, the conceptual model contributes to the fact that the work of the value engineering team becomes focused on the task of maximizing value while saving labor, material and financial resources during the project cycle [6]. At the same time, the input data field in the calculations is expanding accordingly. This, in turn, affects the result of calculating the risk that the construction project (the considered variant of its design) in reality may turn out to be unprofitable for investors. This issue is discussed in more detail in the "Discussion" section. 


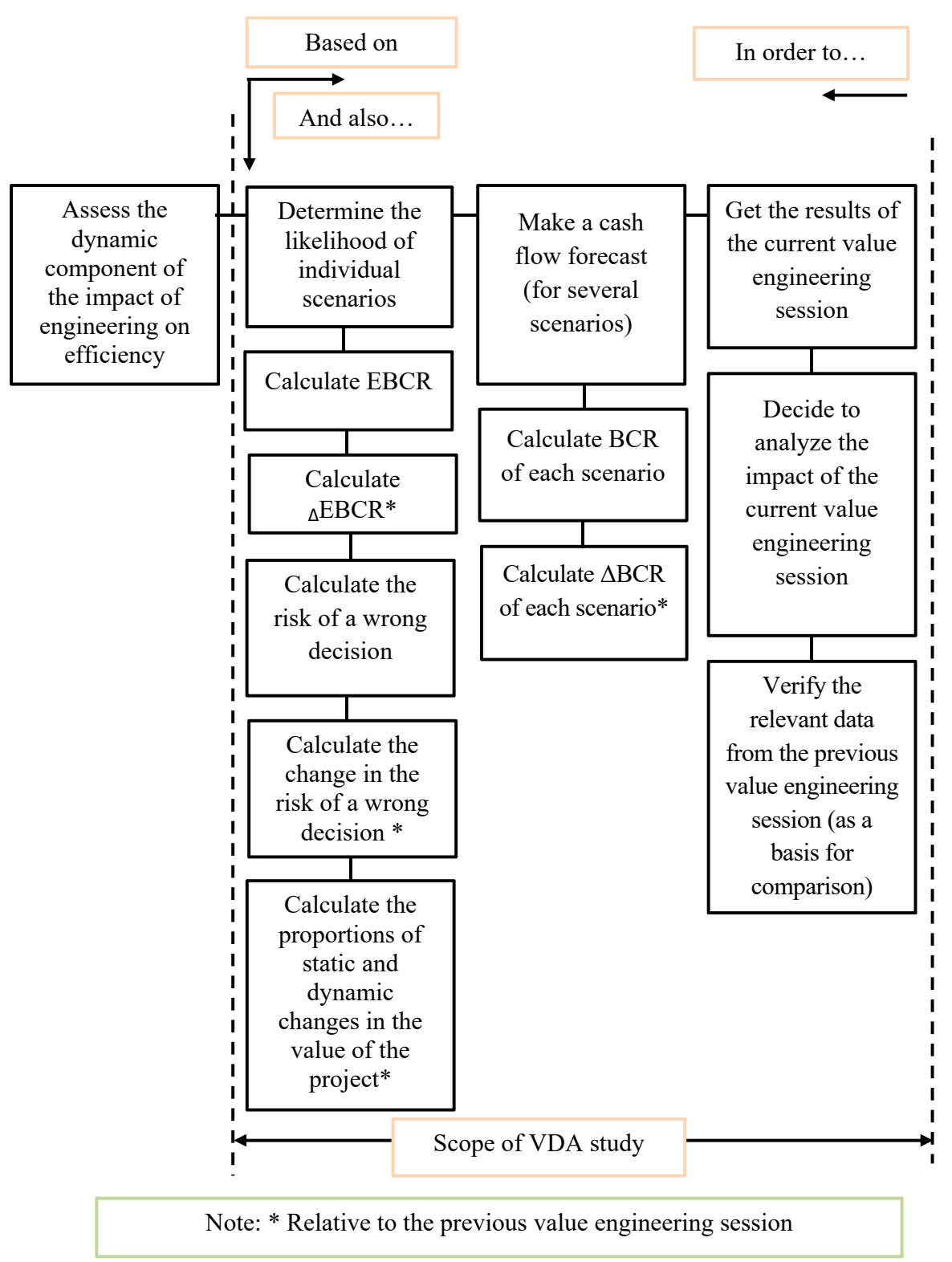

Fig. 2. The procedure for analyzing the dynamics of the value of the project due to engineering under conditions of uncertainty (based on FAST)

\begin{abstract}
5. 3. Description of the proposed model on the example of its application

The steps of the procedure (Fig. 2), in order to reveal the properties and mathematical content of the model will be illustrated on a visual case. In the above example, first of all, an analysis of the financial and economic result of engineering the value of a project is given for the vector of both static and dynamic development. The interpretation of the obtained data from the standpoint of comparing such an engineering change to the project with two other vectors of value enhancement (purely static and purely dynamic) is given in the "Discussion" section. The principal feature of the case is that it reflects the assessment of the dynamics of the value of the project, thanks to engineering, in conditions of uncertainty about the state of the market after the construction object is put into operation.

The cash flow forecast for the average, most expected scenario, as of the considered engineering session is given in Table 1. The forecasting period (life cycle of the project),
\end{abstract}

for the convenience of presenting data in the article, is limited to 11 years.

Total project revenues in the last year of the forecast period take into account residual value. Provided that the criterion interest rate is $12 \%$, the $\mathrm{BCR}$ of the project, calculated on the basis of individual annual total benefits and costs, according to (1), is equal to 1.0574728 . For comparison, the BCR of the project, calculated traditionally on the basis of net cash flows, is 1.145036.

In addition to the most probable scenario, the forecast in conditions of uncertainty, within this case, covers 4 more scenarios, in line with market expectations (level of opti$\mathrm{mism} /$ pessimism). According to these scenarios, during the operational activities of the project benefits and costs are expected in volumes listed in Table 2 .

BCR calculated on the basis of formula (1) is presented in Table 3. As evidenced by the above data, if events follow a pessimistic scenario, then the project will not be profitable for investors (the corresponding BCR is less than one). In 
addition, each of the five scenarios, including the most anticipated one, has its own likelihood.

Table 1

Cash flow forecast reflecting the state of the project before the considered value engineering session (the most anticipated scenario), thousand USD

\begin{tabular}{|c|c|c|c|c|}
\hline Year & $\begin{array}{c}\text { Capital } \\
\text { investment }\end{array}$ & $\begin{array}{c}\text { Operating } \\
\text { income }\end{array}$ & $\begin{array}{c}\text { Operating } \\
\text { expenses }\end{array}$ & $\begin{array}{c}\text { Net cash } \\
\text { flow }\end{array}$ \\
\hline 0 & $-9,600$ & - & - & $-9,600$ \\
\hline 1 & $-14,400$ & - & - & $-14,400$ \\
\hline 2 & $-9,600$ & - & - & $-9,600$ \\
\hline 3 & - & 18,240 & $-10,800$ & 7,440 \\
\hline 4 & - & 18,240 & $-10,800$ & 7,440 \\
\hline 5 & - & 18,240 & $-10,800$ & 7,440 \\
\hline 6 & - & 18,240 & $-10,800$ & 7,440 \\
\hline 7 & - & 18,240 & $-10,800$ & 7,440 \\
\hline 8 & - & 18,240 & $-10,800$ & 7,440 \\
\hline 9 & - & 18,240 & $-10,800$ & 7,440 \\
\hline 10 & - & 18,240 & $-10,800$ & 7,440 \\
\hline 11 & - & 28,240 & $-10,800$ & 17,440 \\
\hline Total & $-33,600$ & 174,160 & $-97,200$ & 43,360 \\
\hline
\end{tabular}

Table 2

Additional forecast scenarios that reflect the status of the project before the analyzed value engineering session, thousand USD

\begin{tabular}{|c|c|c|c|c|}
\hline \multirow{2}{*}{ Indicator } & \multicolumn{4}{|c|}{ Scenarios/options of forecast } \\
\cline { 2 - 5 } & $\begin{array}{c}\text { Opti- } \\
\text { mistic }\end{array}$ & $\begin{array}{c}\text { Relatively } \\
\text { optimistic }\end{array}$ & $\begin{array}{c}\text { Relatively } \\
\text { pessimistic }\end{array}$ & Pessimistic \\
\hline $\begin{array}{c}\text { Income (benefits) } \\
\text { by years 3-10 }\end{array}$ & 25,536 & 22,800 & 16,781 & 14,592 \\
\hline $\begin{array}{c}\text { Income (benefits) in } \\
\text { the 11 }\end{array}$ th year & 39,536 & 35,300 & 25,981 & 22,592 \\
\hline Costs by years 3-11 & $-14,040$ & $-13,176$ & $-10,260$ & $-9,180$ \\
\hline
\end{tabular}

Table 3

Intermediate calculations to determine the EBCR of the project, before the considered value engineering session

\begin{tabular}{|c|c|c|c|c|}
\hline$k$ & Scenario & $\begin{array}{c}\text { Benefit-cost } \\
\text { ratio }\left(\mathrm{BCR}_{k}\right)\end{array}$ & $\begin{array}{c}\text { Scenario } \\
\text { probability } \\
\left(P_{k}\right)\end{array}$ & $\begin{array}{c}\text { The product } \\
\text { of the coeffi- } \\
\text { cient by the } \\
\text { probability } \\
\left(\mathrm{BCR}_{k} \times P_{k}\right)\end{array}$ \\
\hline 1 & Optimistic & 1.25344 & 0.05 & 0.0626719 \\
\hline 2 & $\begin{array}{c}\text { Relatively } \\
\text { optimistic }\end{array}$ & 1.16686 & 0.2 & 0.2333715 \\
\hline 3 & Average & 1.05747 & 0.5 & 0.5287364 \\
\hline 4 & $\begin{array}{c}\text { Relatively } \\
\text { pessimistic }\end{array}$ & 1.00316 & 0.2 & 0.2006314 \\
\hline 5 & Pessimistic & 0.93022 & 0.05 & 0.0465109 \\
\hline
\end{tabular}

The expected benefit-cost ratio for the project (EBCR) is calculated as the sum of the products of the coefficients and the probabilities (Table 3). Thus, the EBCR of the project, as of the considered engineering session value, is equal to 1.0719221.

Based on the above, the variation $\left(\sigma^{\prime \prime}\right)$ is 0.0055041 , and the standard deviation $(\sigma)$ is 0.0741894 . These two indicators characterize the variance around the EBCR, reflecting both sides of the uncertainty - both the risk that the actual situation will be worse than expected, and the possibility that it will be better.

To assess the risk of a situation when the project will have a BCR less than one, the $Z$ coefficient is calculated:

$$
Z=\frac{1-\mathrm{EBCR}}{\sigma}
$$

According to the case of the value considered in the considered engineering session, the Z-score of the dynamic efficiency of the project was -0.9694 . Accordingly, the probability that in reality the BCR of the project will be less than one is $16.6 \%$ (as shown in Fig. 3).

At the same time, we note that based on the above data, the ENPV project, as of the considered engineering session, was worth 5998.74 thousand USD.

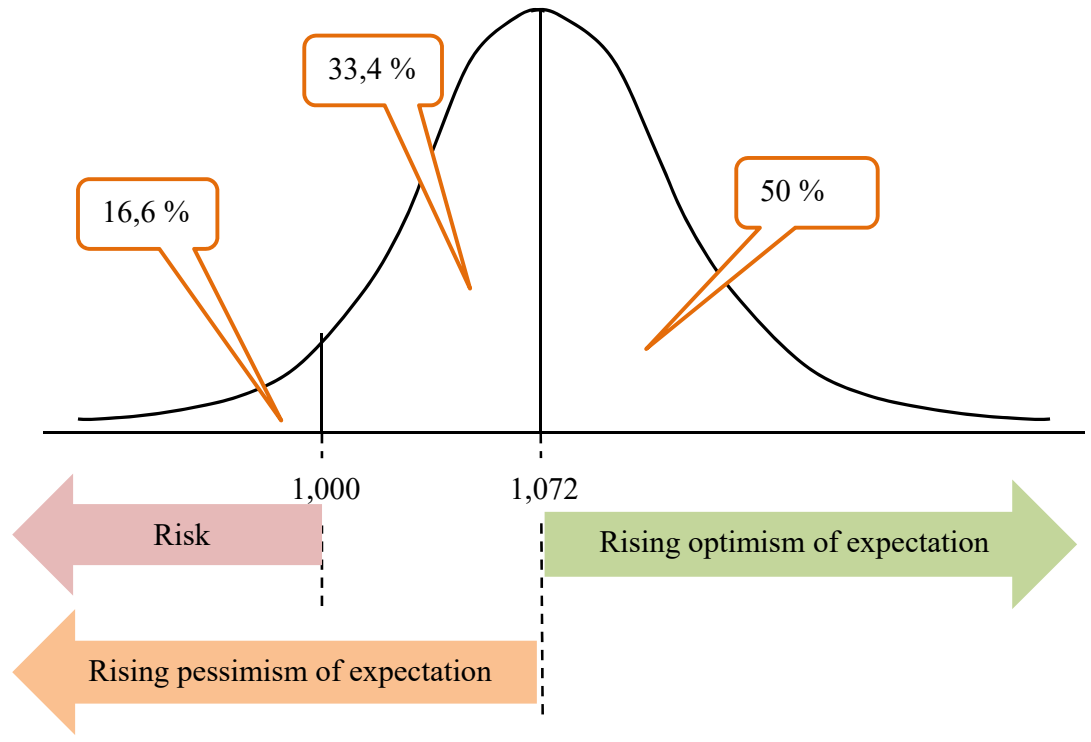

Fig. 3. Area under the normal distribution curve (according to the BCR case under uncertainty, before the considered value engineering session) 
After the considered value engineering session (design improvement), the cash flow for the project on the average, most likely scenario changes (Table 4). Changes occurred both in capital expenditures and in income and expenses during the operation of the construction site. However, the gain in income exceeds the total loss in costs and investments (relative to the state of the project, which was discussed above).

Table 4

Cash flow forecast reflecting the state of the project after the considered value engineering session (the most expected scenario), thousand USD

\begin{tabular}{|c|c|c|c|c|}
\hline Year & $\begin{array}{c}\text { Capital } \\
\text { investment }\end{array}$ & $\begin{array}{c}\text { Operating } \\
\text { income }\end{array}$ & $\begin{array}{c}\text { Operating } \\
\text { expenses }\end{array}$ & $\begin{array}{c}\text { Net cash } \\
\text { flow }\end{array}$ \\
\hline 0 & $-14,400$ & - & - & $-14,400$ \\
\hline 1 & $-21,600$ & - & - & $-21,600$ \\
\hline 2 & $-14,400$ & - & - & $-14,400$ \\
\hline 3 & - & 27,360 & $-15,429$ & 11,931 \\
\hline 4 & - & 27,360 & $-15,429$ & 11,931 \\
\hline 5 & - & 27,360 & $-15,429$ & 11,931 \\
\hline 6 & - & 27,360 & $-15,429$ & 11,931 \\
\hline 7 & - & 27,360 & $-15,429$ & 11,931 \\
\hline 8 & - & 27,360 & $-15,429$ & 11,931 \\
\hline 9 & - & 27,360 & $-15,429$ & 11,931 \\
\hline 10 & - & 27,360 & $-15,429$ & 11,931 \\
\hline 11 & - & 42,360 & $-15,429$ & 26,931 \\
\hline Total & $-50,400$ & 174,160 & $-97,200$ & 71,980 \\
\hline
\end{tabular}

This is the most likely scenario of the "middle line" for constructing four other options for forecasting the development of events: optimistic, relatively optimistic, relatively pessimistic and pessimistic (Table 5). These scenarios reflect the benefits and costs during the operational activities of the construction site, with updated technological design solutions, in accordance with certain market conditions.

Table 5

Additional forecast scenarios reflecting the state of the project after the considered engineering session value, thousand USD

\begin{tabular}{|c|c|c|c|c|}
\hline \multirow{2}{*}{ Indicator } & \multicolumn{4}{|c|}{ Scenarios/options of forecast } \\
\cline { 2 - 5 } & $\begin{array}{c}\text { Opti- } \\
\text { mistic }\end{array}$ & $\begin{array}{c}\text { Relatively } \\
\text { optimistic }\end{array}$ & $\begin{array}{c}\text { Relative- } \\
\text { ly pessi- } \\
\text { mistic }\end{array}$ & $\begin{array}{c}\text { Pessi- } \\
\text { mistic }\end{array}$ \\
\hline $\begin{array}{c}\text { Income (benefits) } \\
\text { by years 3-10 }\end{array}$ & 38,304 & 34,200 & 25,171 & 21,888 \\
\hline $\begin{array}{c}\text { Income (benefits) in } \\
\text { the 11 } 11^{\text {th }} \text { year }\end{array}$ & 59,304 & 52,950 & 38,971 & 33,888 \\
\hline Costs by years 3-11 & $-20,058$ & $-18,823$ & $-14,657$ & $-13,115$ \\
\hline
\end{tabular}

The conducted value engineering session led to the growth of BCR (Table 6). According to some scenarios, the change in the "benefit-cost" ratio in comparison with the previous state of the project is: ${ }_{\Delta} \mathrm{BCR}_{1}=0.04094$ or $3.27 \%$; ${ }_{\Delta} \mathrm{BCR}_{2}=0.03726$ or $3.19 \% ;{ }_{\Delta} \mathrm{BCR}_{3}=0.03129$ or $2.96 \%$; ${ }_{\triangle} \mathrm{BCR}_{4}=0.02906$ or $2.90 \% ;{ }_{\Delta} \mathrm{BCR}_{5}=0.02567$ or $2.76 \%$. So there is a tendency: the more pessimistic the scenario, the less impact the engineering session has on its BCR. In addi- tion, as evidenced by the data in the case, if events follow the most pessimistic scenario, the project will remain unprofitable for investors.

Table 6

Interim calculations to determine the EBCR of the project, the state after the considered engineering session value

\begin{tabular}{|c|c|c|c|c|}
\hline$k$ & Scenario & $\begin{array}{c}\text { Benefit-cost } \\
\text { ratio }\left(\mathrm{BCR}_{k}\right)\end{array}$ & $\begin{array}{c}\text { Scenario } \\
\text { probabil- } \\
\text { ity }\left(P_{k}\right)\end{array}$ & $\begin{array}{c}\text { The product of the } \\
\text { coefficient by the prob- } \\
\text { ability }\left(\mathrm{BCR}_{k} \times P_{k}\right)\end{array}$ \\
\hline 1 & Optimistic & 1.29438 & 0.05 & 0.0647189 \\
\hline 2 & $\begin{array}{c}\text { Relatively } \\
\text { optimistic }\end{array}$ & 1.20412 & 0.2 & 0.2408245 \\
\hline 3 & Average & 1.08876 & 0.5 & 0.5443799 \\
\hline 4 & $\begin{array}{c}\text { Relatively } \\
\text { pessimistic }\end{array}$ & 1.03221 & 0.2 & 0.2064426 \\
\hline 5 & Pessimistic & 0.95589 & 0.05 & 0.0477946 \\
\hline
\end{tabular}

The sum of the products of $\mathrm{BCR}_{\mathrm{k}}$ by the probabilities of the respective scenarios gives the EBCR, which in this case is equal to 1.1041605 . So, thanks to the results of the engineering session, the change in the expected "benefit-cost" ratio $\triangle \mathrm{EBCR}=0.0322384$, which indicates a positive trend in the value of the project.

Now, according to the procedure, it is possible to analyze how the engineering session impact on investment risk. Based on the data given in Table 6, for this state of the project (this design option), the variation $\left(\sigma^{\prime \prime}\right)$ is 0.0060607 , the standard deviation $(\sigma)$ is 0.0778503 , and the $Z$ coefficient is -1.337959708 . Therefore, the risk that the BCR of the project will be less than one is $12.1 \%$. Thus, although the standard deviation has increased, the investment risk calculated using the benefit-cost ratio has decreased by $4.5 \%$.

So, the considered value engineering session led to a dynamic increase in project efficiency and a decrease in the risk that the funds invested in the project will bring insufficient benefits per unit of cost throughout the entire project cycle. And as emphasized in [45], project management in general aims to increase the likelihood of project success.

At the same time, let's note that based on the above data, the ENPV project, the state after the considered cost engineering session, became equal to 12409.33 thousand dollars. USA.

Presented in Tables 4-6 the considered value engineerd ing session (design improvement) led to a change in the efficiency of the project in such a way that both its scale and the ratio of benefits to costs changed.

To determine the share of the value increase that is achieved due to purely dynamic factors, hover over a design option, which brings the project to the appropriate isovalue line, but without the static factor. Table 7 shows the data when the value engineering session led only to a decrease in costs during the operational activity of the construction object (compared to the situation presented in Table 1).

According to other scenarios, according to this variant of the result of the value engineering session, during the operational activity of the project, the benefits and costs are expected in volumes indicated in Table 8. 
Table 7 efit analysis and the theory of the dynamics of the value of

Cash flow forecast reflecting the state of the project after the considered session of value engineering: purely dynamic change (the most expected scenario), thousand USD

\begin{tabular}{|c|c|c|c|c|}
\hline Year & $\begin{array}{c}\text { Capital } \\
\text { investment }\end{array}$ & $\begin{array}{c}\text { Operating } \\
\text { income }\end{array}$ & $\begin{array}{c}\text { Operating } \\
\text { expenses }\end{array}$ & $\begin{array}{c}\text { Net cash } \\
\text { flow }\end{array}$ \\
\hline 0 & $-9,600$ & - & - & $-9,600$ \\
\hline 1 & $-14,400$ & - & - & $-14,400$ \\
\hline 2 & $-9,600$ & - & - & $-9,600$ \\
\hline 3 & - & 18,240 & $-10,286$ & 7,954 \\
\hline 4 & - & 18,240 & $-10,286$ & 7,954 \\
\hline 5 & - & 18,240 & $-10,286$ & 7,954 \\
\hline 6 & - & 18,240 & $-10,286$ & 7,954 \\
\hline 7 & - & 18,240 & $-10,286$ & 7,954 \\
\hline 8 & - & 18,240 & $-10,286$ & 7,954 \\
\hline 9 & - & 18,240 & $-10,286$ & 7,954 \\
\hline 10 & - & 18,240 & $-10,286$ & 7,954 \\
\hline 11 & - & 28,240 & $-10,286$ & 17,954 \\
\hline Total & $-33,600$ & 174,160 & $-92,573$ & 47,987 \\
\hline
\end{tabular}

Table 8

Additional forecast scenarios reflecting the state of the project after the considered session of value engineering: purely dynamic change, thousand USD

\begin{tabular}{|c|c|c|c|c|}
\hline \multirow{2}{*}{ Indicator } & \multicolumn{4}{|c|}{ Scenarios/options of forecast } \\
\cline { 2 - 5 } & $\begin{array}{c}\text { Opti- } \\
\text { mistic }\end{array}$ & $\begin{array}{c}\text { Relatively } \\
\text { optimistic }\end{array}$ & $\begin{array}{c}\text { Relatively } \\
\text { pessimistic }\end{array}$ & $\begin{array}{c}\text { Pessi- } \\
\text { mistic }\end{array}$ \\
\hline $\begin{array}{c}\text { Income (benefits) by } \\
\text { years 3-10 }\end{array}$ & 25,536 & 22,800 & 16,781 & 14,592 \\
\hline $\begin{array}{c}\text { Income (benefits) in } \\
\text { the 11 }\end{array}$ th year & 39,536 & 35,300 & 25,981 & 22,592 \\
\hline Costs by years 3-11 & $-13,372$ & $-12,549$ & $-9,772$ & $-8,743$ \\
\hline
\end{tabular}

For specified in Tables 7, 8 case, the data of intermediate calculations for determining the EBCR project will be the same as indicated in Table 6. So, the EBCR of the project is 1.1041605 , and the corresponding investment risk is $12.1 \%$. Thus, the effectiveness of the project is on the same line of isovalues as in the situation after the engineering, presented in Tables 4-6. At the same time, the ENPV project was equal to 8272.89 thousand USD. The entire increase in this indicator $(\triangle \mathrm{ENPV}=2274.1489$ thousand USD) in comparison with the state before the considered session of value engineering took place due to the dynamic factor of the development of the project.

Now we can return to the analysis of the situation when the engineering session led to both static and dynamic changes in the value of the project (Tables $4-6$ ). The cale culation of the proportion of the two vectors of change in value (static and dynamic) in the total volume of improving the efficiency of the project is presented in Table 9 . In this part of the assessment of the financial and economic result of the conducted engineering session, the analysis will be asked mainly for $\triangle \mathrm{ENPV}$, and not for $\triangle \mathrm{EBCR}$, since it is this indicator that reflects both directions of the project's development - both dynamic and static. However, the EBCR fulfills an important supporting function by determining the corresponding project cost states on the same isovalue line using this criterion. So, within the framework of the "Crystal" value management, at this stage of the assessment, there is a synergistic application of the cost-ben-

Table 9

Calculation of the proportion of static and dynamic changes in the value of the project, according to the case

\begin{tabular}{|c|c|c|}
\hline $\begin{array}{c}\text { Engineering development } \\
\text { factor for the project }\end{array}$ & $\begin{array}{c}\Delta \mathrm{ENPV}, \text { thousand } \\
\text { USD }\end{array}$ & $\Delta \mathrm{ENPV}, \%$ \\
\hline Total growth & 6410.59 & $100 \%$ \\
\hline Dynamic component & 2274.14 & $35.47 \%$ \\
\hline Static component & 4136.44 & $64.53 \%$ \\
\hline
\end{tabular}

Notes (explanation to the calculation): ENPV of the project as before and after the engineering session was 5998.74 and 12409.33 thousand USD, respectively. Thus, the total increase in value is equal to 6410.59 thousand USD. The situation with the purely dynamic development discussed above brings the project to the same isovalue (EBCR of the project in both cases is equal to 1.1041605). Thus, the dynamic component of value growth, as shown above, is 2274.14 thousand USD, or $35.47 \%$ of the total. The rest of the increase in the value of the projf ect is caused by the static factor of design development

The following should also be emphasized here. A change in design can cause revenues and expenses to change, but a net meal flow will not. An example of such a situation is presented in Table 10 (compared with Table 1).

Table 10

Cash flow forecast for an alternative design solution (most expected scenario), thousand USD

\begin{tabular}{|c|c|c|c|c|}
\hline Year & $\begin{array}{c}\text { Capital } \\
\text { investment }\end{array}$ & $\begin{array}{c}\text { Operating } \\
\text { income }\end{array}$ & $\begin{array}{c}\text { Operating } \\
\text { expenses }\end{array}$ & $\begin{array}{c}\text { Net cash } \\
\text { flow }\end{array}$ \\
\hline 0 & $-9,600$ & - & - & $-9,600$ \\
\hline 1 & $-14,400$ & - & - & $-14,400$ \\
\hline 2 & $-9,600$ & - & - & $-9,600$ \\
\hline 3 & - & 20,240 & $-12,800$ & 7,440 \\
\hline 4 & - & 20,240 & $-12,800$ & 7,440 \\
\hline 5 & - & 20,240 & $-12,800$ & 7,440 \\
\hline 6 & - & 20,240 & $-12,800$ & 7,440 \\
\hline 7 & - & 20,240 & $-12,800$ & 7,440 \\
\hline 8 & - & 20,240 & $-12,800$ & 7,440 \\
\hline 9 & - & 20,240 & $-12,800$ & 7,440 \\
\hline 10 & - & 18,240 & $-10,800$ & 7,440 \\
\hline 11 & - & 28,240 & $-10,800$ & 17,440 \\
\hline Total & $-33,600$ & 188,160 & $-111,200$ & 43,360 \\
\hline
\end{tabular}

The peculiarities of calculating BCR using the conceptual model, in contrast to traditional approaches, will reveal the impact of such a change on the project efficiency. For the alternative presented in Table 10 this indicator will be equal to 1.0524501 , which differs from the alternative presented in Table 1, where it was 1.0574728 .

\section{Discussion of the results of the development of a model for analyzing the dynamics of the value of the project in conditions of uncertainty}

So, according to the design improvement option presented in Tables 4-6, the result of the work of the value engineering team was both a static and a dynamic change 
in the resulting effect. However, there are two conceptually different outcomes possible.

First, the value of a project can be changed purely statically. If, as a result of the engineering session, the scale of the project simply increased, then this will not lead to a change in $\mathrm{BCR}_{k}$ according to the corresponding scenarios. Consequently, neither the EBCR nor the risk that the project will be ineffective will change. For example, with an increase in the scale of the project, the cash flow data for which is given in tables 1, 2, 1.5 times, EBCR will remain at 1.0719221, and the corresponding risk - at $16.6 \%$. On the other hand, $\mathrm{NPV}_{k}$ for each of the scenarios and the ENPV calculated on their basis will increase by 1.5 times. At the same time, the probability of a negative NPV value will remain unchanged at $17.62 \%$. Thus, in this case, all $100 \%$ increase in ENPV will take place due to the static vector of the project's development.

Secondly, the project can be changed by engineering so that its value increases purely dynamically. If, for example, as a result of a cost engineering session, the amount of capital costs was reduced without changing all other parameters of the project, then there was a purely dynamic increase in value. In the case presented in Tables 7,8 , when, thanks to innovations, it was possible to reduce costs during the operation of the construction object without changing other parameters of the project, all $100 \%$ increase in ENPV oce curred due to the dynamic vector of development.

For the case when design improvement has led to both dynamic and static changes in the value of the project, the model allows to calculate the proportion of two vectors of influence of design improvement on efficiency. In the option presented in Tables 4-6 and 9, the share of the dynamic vector is $35.47 \%$, and the static one, respectively $-64.53 \%$.

It should be noted here that, as indicated in [6], the dynamic factors of value growth based on the results of the design improvement session include measures for introducing innovations and proposals for organizational and technological rationalization. The rest of the changes (for example, the increase in the scale of the project, the use of more expensive materials) are of a static nature.

The proposed conceptual model gains important properties due to the fact that the BCR calculation is based not on net cash flows, but on annual total benefits and annual total costs (1). To illustrate the resulting effect, the situation can be considered, the data for which are presented in Tables 1 and 10. Options that are presented in Tables 1 and 10, have the same net cash flows. However, the second option (Table 10) is characterized by a greater burden on the nature of the project - both revenues and expenses in the years from the $3^{\text {rd }}$ to the $10^{\text {th }}$ are mirroredly increased by 2 million USD.

So, if BCR (or PI profitability index), when the interest rate is $12 \%$, is calculated based on net cash flows, then according to the options presented in Tables 1, 10, we get the same result -1.145036 . However, if BCR is calculated on the basis of annual total benefits and annual total costs, then the second option will result in 1.0524501, which is 0.005023 less (worse) than the first option (Table 1 comment). This is a value reflection of the fact that the second option (the second alternative) bears an increased burden on the nature of the project.

At the same time, this positive "ecological" property of the proposed approach to calculating BCR (EBCR) has a downside. In the case when the calculations of both ENPV and EBCR are based on the net cash flows for the project, the resulting risk assessment of making an erroneous investment decision for both indicators will be the same. So, for example, according to the option indicated in Tables 7 and 8 , according to the traditional approach to calculations, both the probability of negative NPV and the probability of $\mathrm{BCR}$, less than one, is $10.92 \%$. However, when calculating the BCR (EBCR) based on the annual total benefits and the annual total costs, the probability of BCR, less than one, would be different. In the situation under consideration, the probability of making an erroneous investment decision according to this criterion is $12.10 \%$. This result is explained by the increased field of input data for calculations and, again, reflects the presence of risks of the project's impact on the environment.

Let's also emphasize that the proposed approach is aimed primarily at stimulating a dynamic growth in the value of the project, which is measured by the $\triangle \mathrm{BCR}$ indicator. Such growth is possible even if the new design reduces the scale of the project. So, the proposed model corresponds to the current trend of bias in the perception of the design value "from bigger is better to smaller is cooler", indicated in [47].

The results obtained in comparison with [6] differ due to the fact that the analysis is carried out not on the basis of a deterministic cash flow, but on the basis of a multivariate forecast. This is graphically displayed by a set of isovalue lines (Fig. 1). Thus, the conceptual model is more consistent with the conditions that exist in the real world with turbulent development characteristics. In addition, the proposed procedure is based on the FAST principles (Fig. 2). And this creative tool is one of the key values in engineering [35].

In contrast to the EGVM approach [31], the proposed model takes into account the cost of money over time and is an assessment of the economic efficiency of the project. Due to this, the analysis complies with the basic investment principles and allows a comparative account of the benefits and costs that will occur in different years of the project's life cycle.

This study has the following limitations:

- the study concerns only projects that have a long life cycle (that is, for which it is advisable to use discounted cash flows);

- the model can be applied only in projects for which it is possible to determine in monetary form not only costs, but also benefits;

- the study was carried out on the example of a construction project and does not cover other types of projects.

Further development of the study is possible in the following directions:

- development of a model for projects that relate not to construction, but to other areas of activity;

- study of the cumulative interaction of the conceptual model with all other facets of the "Project value management crystal" [46].

Summing up, the key features of the proposed conceptual model should be highlighted:

- the model allows to analyze the dynamics of the value of the project in conditions of uncertainty and risks;

- the study mathematically proves that the more pessimistic the scenario, the less impact the design improvement has on it;

- the approach allows to calculate the proportions of dynamic and static changes in the value of the design;

- increasing the value of the design while reducing the scale of the project in the context of the logic of sustainable development can be considered the best solution. 
The practical value of the proposed model is as follows. Since the analysis is based on metrics that are logically consistent with the corresponding foundations of the SAVE International methodology, the model will facilitate the effective work of value engineering teams. These teams include inverters that evaluate projects based on BCR and NPV. So, investors and engineers will have a common basis for making decisions. In addition, since the analysis is based on a number of possible scenarios, the model reflects the probabilistic nature of events. This will facilitate the adoption of the most appropriate decisions, taking into account the risks in modern conditions of turbulent development. Another element of the practical value of the work is the focus of the model on environmental protection and resource conservation. In the face of aggravated environmental problems, this aspect of the model is very useful.

\section{Conclusions}

1. Under conditions of uncertainty, the isovalue line is the locus of points at which different combinations of the four dimensions of the time-benefit-cost-risk space give the same BCR, with a certain degree of optimism about the project's cash flow. The scenario based on the balance of optimism and pessimism is the most probable and key one. The more pessimistic the expectations are, the closer to the origin the corresponding isovalue line becomes. In addition, the further the isovalue is located from the key line, the less likely such a scenario of events is. With an increase in the efficiency of a project due to engineering, the entire array of isovalue lines (for the entire set of forecast scenarios) changes its geometrical position, moving further from the origin of coordinates of the corresponding space.

2 . The analysis of value in the face of uncertainty consists of three stages. The implementation of the first stage ensures the receipt of incoming information, allows you to reasonably initiate an assessment of the dynamics of value. The implementation of the second stage provides a multivariate forecast of cash flows, allows you to calculate BCR and $\triangle \mathrm{BCR}$ for each scenario of the expected conditions for the implementation of the project. The implementation of the third stage provides the calculation of EBCR and $\triangle E B C R$, an assessment of the risk of making an erroneous investment decision and a change in such risk as a result of the engineering session, the calculation of the achieved proportion of statics and dynamics in the change in the value of the project.

3 . The conceptual analytical model is characterized by the fact that the assessment of the success of the value engineering team is carried out on the basis of the annual total benefits and the annual total costs during the project cycle. Thus, the analysis takes into account the environmental impact of the project. The specified property of the model under conditions of uncertainty manifests itself in the analysis of both changes in EBCR and changes in the risk of making an erroneous decision. The synergistic application of cost-benefit analysis and the theory of value dynamics make it possible to calculate the proportion of two vectors of value change (static and dynamic) in the total volume of project efficiency improvement. The given case testifies to the possibility of using the proposed model in the practice of engineering the value of construction projects.

\section{References}

1. Friedman, K., Lou, Y., Ma, J. (2015). Shè Jì: The Journal of Design, Economics, and Innovation. She Ji: The Journal of Design, Economics, and Innovation, 1 (1), 1-4. doi: https://doi.org/10.1016/j.sheji.2015.09.002

2. Schwab, K., Malleret, T. (2020). COVID-19: The Great Reset. ISBN Agentur Schweiz, 280.

3. Poggenpohl, S. H. (2017). Blindspots in Economics and Design: A Review of John Heskett's Design and the Creation of Value. She Ji: The Journal of Design, Economics, and Innovation, 3 (4), 251-261. doi: https://doi.org/10.1016/j.sheji.2018.02.002

4. Integrated Project Delivery: A Guide. AIA. Available at: https://www.aia.org/resources/64146-integrated-project-delivery-a-guide

5. Roos, G. (2016). Design-Based Innovation for Manufacturing Firm Success in High-Cost Operating Environments. She Ji: The Journal of Design, Economics, and Innovation, 2 (1), 5-28. doi: https://doi.org/10.1016/j.sheji.2016.03.001

6. Bugrov, O., Bugrova, O. (2020). Control process development on the ground of project value dynamics laws. Technology Audit and Production Reserves, 2 (4 (52)), 11-19. doi: https://doi.org/10.15587/2706-5448.2020.200995

7. Lee, S. M., Trimi, S. (2018). Innovation for creating a smart future. Journal of Innovation \& Knowledge, 3 (1), 1-8. doi: https:// doi.org/10.1016/j.jik.2016.11.001

8. Bos-de Vos, M., Volker, L., Wamelink, H. (2019). Enhancing value capture by managing risks of value slippage in and across projects. International Journal of Project Management, 37 (5), 767-783. doi: https://doi.org/10.1016/j.ijproman.2018.12.007

9. Iliescu, M., Ciocan, R. (2017). Modern Technologies Innovation in Use for Quality Control on Construction Site. Procedia Engineering, 181, 999-1004. doi: https://doi.org/10.1016/j.proeng.2017.02.499

10. Buchanan, R. (2015). Worlds in the Making: Design, Management, and the Reform of Organizational Culture. She Ji: The Journal of Design, Economics, and Innovation, 1 (1), 5-21. doi: https://doi.org/10.1016/j.sheji.2015.09.003

11. Martinsuo, M., Klakegg, O. J., van Marrewijk, A. (2019). Editorial: Delivering value in projects and project-based business. International Journal of Project Management, 37 (5), 631-635. doi: https://doi.org/10.1016/j.ijproman.2019.01.011

12. Vesic-Vasovic, J., Radojicic, M., Nesic, Z., Mihailovic, D. (2014). Possibility of choosing development investment programs of a production company by applying discounted investment appraisal technique. Journal of Engineering Management and Competitiveness, 4 (1), 41-46. doi: https://doi.org/10.5937/jemc1401041v

13. Volden, G. H. (2019). Assessing public projects' value for money: An empirical study of the usefulness of cost-benefit analyses in decision-making. International Journal of Project Management, 37 (4), 549-564. doi: https://doi.org/10.1016/ j.ijproman.2019.02.007 
14. Wu, D., Ma, X., Zhang, S., Ma, J. (2019). Are more economic efficient solutions ignored by current policy: Cost-benefit and NPV analysis of coal-fired power plant technology schemes in China. Ecological Indicators, 103, 105-113. doi: https://doi.org/10.1016/ j.ecolind.2019.02.039

15. Gaspars-Wieloch, H. (2017). Project Net Present Value estimation under uncertainty. Central European Journal of Operations Research, 27 (1), 179-197. doi: https://doi.org/10.1007/s10100-017-0500-0

16. Bilqist, R. A., Dachyar, M., Farizal, F. (2018). Project Valuation in the Geothermal Power Plant Project: A Comparison of Expected Net Present Value and Static Net Present Value Approaches. SSRN Electronic Journal. doi: https://doi.org/10.2139/ssrn.3248120

17. Casady, C. B., Gómez-Ibáñez, J. A., Schwimmer, E. (2020). Toll-managed lanes: A simplified benefit-cost analysis of seven US projects. Transport Policy, 89, 38-53. doi: https://doi.org/10.1016/j.tranpol.2020.02.001

18. Alsultan, M., Jun, J., Lambert, J. H. (2020). Program evaluation of highway access with innovative risk-cost-benefit analysis. Reliability Engineering \& System Safety, 193, 106649. doi: https://doi.org/10.1016/j.ress.2019.106649

19. Kahraman, C., Tolga, E., Ulukan, Z. (2000). Justification of manufacturing technologies using fuzzy benefit/cost ratio analysis. International Journal of Production Economics, 66 (1), 45-52. doi: https://doi.org/10.1016/s0925-5273(99)00103-6

20. Garrote, J., Bernal, N., Díez-Herrero, A., Martins, L. R., Bodoque, J. M. (2019). Civil engineering works versus self-protection measures for the mitigation of floods economic risk. A case study from a new classification criterion for cost-benefit analysis. International Journal of Disaster Risk Reduction, 37, 101157. doi: https://doi.org/10.1016/j.ijdrr.2019.101157

21. Pivorienè, A. (2017). Real Options and Discounted Cash Flow Analysis to Assess Strategic Investment Projects. Economics and Business, 30 (1), 91-101. doi: https://doi.org/10.1515/eb-2017-0008

22. Martinuzzi, A., Blok, V., Brem, A., Stahl, B., Schönherr, N. (2018). Responsible Research and Innovation in Industry - Challenges, Insights and Perspectives. Sustainability, 10 (3), 702. doi: https://doi.org/10.3390/su10030702

23. Cao, Y., Wan, N., Zhang, H., Zhang, X., Zhou, Q. (2020). Linking environmental regulation and economic growth through technological innovation and resource consumption: Analysis of spatial interaction patterns of urban agglomerations. Ecological Indicators, 112, 106062. doi: https://doi.org/10.1016/j.ecolind.2019.106062

24. Sofia, D., Gioiella, F., Lotrecchiano, N., Giuliano, A. (2020). Cost-benefit analysis to support decarbonization scenario for 2030: A case study in Italy. Energy Policy, 137, 111137. doi: https://doi.org/10.1016/j.enpol.2019.111137

25. Kong, L., Ma, B. (2020). Evaluation of environmental impact of construction waste disposal based on fuzzy set analysis. Environmental Technology \& Innovation, 19, 100877. doi: https://doi.org/10.1016/j.eti.2020.100877

26. Manzoor, T., Rovenskaya, E., Muhammad, A. (2016). Game-theoretic insights into the role of environmentalism and social-ecological relevance: A cognitive model of resource consumption. Ecological Modelling, 340, 74-85. doi: https://doi.org/10.1016/ j.ecolmodel.2016.09.007

27. Hendiani, S., Bagherpour, M., Mahmoudi, A., Liao, H. (2020). Z-number based earned value management (ZEVM): A novel pragmatic contribution towards a possibilistic cost-duration assessment. Computers \& Industrial Engineering, 143, 106430. doi: https://doi.org/10.1016/j.cie.2020.106430

28. Muriana, C., Vizzini, G. (2017). Project risk management: A deterministic quantitative technique for assessment and mitigation. International Journal of Project Management, 35 (3), 320-340. doi: https://doi.org/10.1016/j.ijproman.2017.01.010

29. Durga Sruthi, M., Aravindan, A. (2020). Performance measurement of schedule and cost analysis by using earned value management for a residential building. Materials Today: Proceedings, 33, 524-532. doi: https://doi.org/10.1016/j.matpr.2020.05.210

30. Mishakova, A., Vakhrushkina, A., Murgul, V., Sazonova, T. (2016). Project Control Based on a Mutual Application of Pert and Earned Value Management Methods. Procedia Engineering, 165, 1812-1817. doi: https://doi.org/10.1016/j.proeng.2016.11.927

31. Koke, B., Moehler, R. C. (2019). Earned Green Value management for project management: A systematic review. Journal of Cleaner Production, 230, 180-197. doi: https://doi.org/10.1016/j.jclepro.2019.05.079

32. Khodeir, L. M., El Ghandour, A. (2019). Examining the role of value management in controlling cost overrun [application on residential construction projects in Egypt]. Ain Shams Engineering Journal, 10 (3), 471-479. doi: https://doi.org/10.1016/ j.asej.2018.11.008

33. Cherrier, H., Türe, M. (2020). Value dynamics in ordinary object disposal. Journal of Business Research, 116, 221-228. doi: https:// doi.org/10.1016/j.jbusres.2020.05.022

34. Odimabo, O., Oduoza, C. F. (2018). Guidelines to Aid Project Managers in Conceptualising and Implementing Risk Management in Building Projects. Procedia Manufacturing, 17, 515-522. doi: https://doi.org/10.1016/j.promfg.2018.10.091

35. Value Standard and Body of Knowledge (2007). SAVE International. Available at: http://www.pinnacleresults.com/images/ VE_Standard_from_SAVE.pdf

36. Paquin, J.-P., Gauthier, C., Morin, P.-P. (2016). The downside risk of project portfolios: The impact of capital investment projects and the value of project efficiency and project risk management programmes. International Journal of Project Management, 34 (8), 1460-1470. doi: https://doi.org/10.1016/j.ijproman.2016.07.009

37. Wang, L., Kunc, M., Bai, S. (2017). Realizing value from project implementation under uncertainty: An exploratory study using system dynamics. International Journal of Project Management, 35 (3), 341-352. doi: https://doi.org/10.1016/j.ijproman.2017.01.009

38. Willumsen, P., Oehmen, J., Stingl, V., Geraldi, J. (2019). Value creation through project risk management. International Journal of Project Management, 37 (5), 731-749. doi: https://doi.org/10.1016/j.ijproman.2019.01.007 
39. Lambert, M., Riera, B., Martel, G. (1999). Application of functional analysis techniques to supervisory systems. Reliability Engineering \& System Safety, 64 (2), 209-224. doi: https://doi.org/10.1016/s0951-8320(98)00064-7

40. Boehnert, J. (2018). Anthropocene Economics and Design: Heterodox Economics for Design Transitions. She Ji: The Journal of Design, Economics, and Innovation, 4 (4), 355-374. doi: https://doi.org/10.1016/j.sheji.2018.10.002

41. Hensher, M. (2020). Incorporating environmental impacts into the economic evaluation of health care systems: Perspectives from ecological economics. Resources, Conservation and Recycling, 154, 104623. doi: https://doi.org/10.1016/j.resconrec.2019.104623

42. González Jiménez, L., Blanco Pascual, L. (2008). Multicriteria cash-flow modeling and project value-multiples for two-stage project valuation. International Journal of Project Management, 26 (2), 185-194. doi: https://doi.org/10.1016/j.ijproman.2007.03.012

43. Keshk, A. M., Maarouf, I., Annany, Y. (2018). Special studies in management of construction project risks, risk concept, plan building, risk quantitative and qualitative analysis, risk response strategies. Alexandria Engineering Journal, 57 (4), 3179-3187. doi: https://doi.org/10.1016/j.aej.2017.12.003

44. Buehring, J., Bishop, P. C. (2020). Foresight and Design: New Support for Strategic Decision Making. She Ji: The Journal of Design, Economics, and Innovation, 6 (3), 408-432. doi: https://doi.org/10.1016/j.sheji.2020.07.002

45. Sanchez, F., Bonjour, E., Micaelli, J.-P., Monticolo, D. (2020). An Approach Based on Bayesian Network for Improving Project Management Maturity: An Application to Reduce Cost Overrun Risks in Engineering Projects. Computers in Industry, 119, 103227. doi: https://doi.org/10.1016/j.compind.2020.103227

46. Bugrov, O., Bugrova, O. (2017). Formation of a cumulative model for managing the value of construction projects. Eastern-European Journal of Enterprise Technologies, 5 (3 (89)), 14-22. doi: https://doi.org/10.15587/1729-4061.2017.110112

47. Whitney, P. (2015). Design and the Economy of Choice. She Ji: The Journal of Design, Economics, and Innovation, 1 (1), 58-80. doi: https://doi.org/10.1016/j.sheji.2015.09.001 